\title{
Osmotic Power Plant: Process Innovation and Future Potential
}

\author{
Ali Altaee ${ }^{1 *}$, John Zou ${ }^{1}$, Adnan Alhathal Alanezi ${ }^{2}$ and Alaa H Hawari ${ }^{3}$ \\ ${ }^{1}$ School of Civil and Environmental Engineering, University of Technology Sydney, Australia \\ ${ }^{2}$ Department of Chemical Engineering Technology, The Public Authority for Applied Education and Training (PAAET), Kuwait \\ ${ }^{3}$ Department of Civil and Architectural Engineering, Qatar University, Qatar
}

Submission: February 12, 2018; Published: February 20, 2018

*Corresponding author: Ali Altaee, School of Civil and Environmental Engineering, University of Technology Sydney, 13 Broadway, Ultimo, NSW 2007, Australia, Tel: +61420606500; Email: ali.altaee@uts.edu.au

\begin{abstract}
Osmotic power plant operating by Pressure Retarded Osmosis (PRO) is a promising technology for power generation from renewable resources. A wealth of literature has been published in PRO feasibility to replace conventional fossil fuel power plants. In this paper the PRO and the new innovative Dual Stage PRO process are briefly reviewed with the authors' insight on the future development and application of the PRO power plants.
\end{abstract}

\section{Introduction}

Pressure retarded Osmosis (PRO) has been firstly proposed by Sydney Loeb [1] and it represents the energy of mixing a concentrated brine solution with a diluted solution. In practice, osmotic energy can be harvested by the PRO when concentrated and diluted solutions are separated by a selective semi permeable membrane that allows water movement but rejects most of the ionic species [2]. The concentrated solution (draw solution) is pressurized and pumped into the PRO membrane, which separates the draw solution from the diluted solution (feed solution). The osmotic pressure difference between the draw and feed solution induces fresh water movement across the membrane diluting the draw solution. The pressurized draw solution, then, goes to a special hydro-turbine system for power generation. Experimentally, the PRO process is a viable technology but most of the work was in a laboratory scale and few pilot plants have been carried out [3-5]. The advances in membrane technology has resolved the problem of finding a suitable PRO membrane that once has been an impediment for technology demonstration and testing in a field scale. Toyobo is one of the pioneering companies that have successfully manufactured and tested PRO membranes for a large scale pilot plant demonstration [6]. Hollow fiber FO membranes manufactured by Toyobo come with a large active area that reaches $700 \mathrm{~m} 2$ and stands up to 30 bar feed pressure which make them suitable for handling a salinity gradient with 60 bar osmotic pressure difference. This was based on the assumption that power generation by the PRO process reaches a maximum amount at a hydraulic pressure equal to $\Delta P=\Delta \pi / 2$ [4] Experimental work has also revealed the impact of membrane intrinsic properties on the performance of the PRO process [7]. Concentration of the feed solution and dilution of the draw solution, often termed as internal and external concentration polarizations, respectively, has been experimentally measured and found to have a detrimental effect on the process performance [6-7]. Therefore, PRO membranes should be thin enough to reduce the effect of concentration polarization but strong enough to tolerate the hydraulic pressure on the draw solution side of the membrane. Finally, PRO membranes should have a relatively high rejection rate to ionic species to reduce reverse salt diffusion and ions transports from the draw and feed solutions, respectively.

\section{Field Studies}

Few pilot plant studies have been attempted to demonstrate the feasibility of the PRO process in field conditions $[8,9]$. The first pilot plant was carried out by Statkraft Company (Norway) using seawater-fresh water salinity gradient resource [8]. Statkraft has incorporated a pressure exchanger on the draw solution flow in a featured design to reduce the operational energy of the PRO process [8]. Without the pressure exchanger, the PRO process becomes less energy-efficient. Field experiments have also revealed that the minimum power density, that is the energy generated per membrane unit area, should be more than $5 \mathrm{~W} / \mathrm{m}^{2}$ in order for the PRO process to be feasibly economic [8]. The pilot plant test lasted for 2 years before it has been shut 
down in 2011. Statkraft has not revealed the main reasons to call off experiments on the pilot plant but it has been thought it was due to the insufficient osmotic energy of the salinity gradient resource. Despite the unsatisfactory results from the Statkraft PRO plant, the field experiments have demonstrated the feasibility of power generation with the PRO process.

Recently, Mega-tone project has been carried out with Toyobo hollow fiber membranes using Reverse Osmosis (RO) brine-tertiary treated wastewater effluent salinity gradient resource [9]. The pilot plant study revealed the importance of feed water pretreatment to prevent membrane fouling. Initially, Microfiltration (MF) and RO process were performed for the treatment of tertiary treated wastewater but RO fouling has been observed. As such, the wastewater effluent was pretreated by the MF only and was found to be sufficient for the removal of fouling materials from the feed stream to the PRO process. PRO membrane fouling was further reduced by adding a forth port on the feed side of the membrane [10]. Mega-tone project successfully implemented the concept of osmotic power plant with an average power density of $10 \mathrm{~W} / \mathrm{m}^{2}$. This is almost double the threshold reported by the Statkraft Company and required for an economic PRO process.

Kim \& co-workers [11] have tested a spiral wound membrane for power generation from seawater-river water salinity gradient resource. The spiral wound membrane has an axial and spiral flow paths, and net and tricot spacers for draw- and feed-solution streams, respectively. Draw solution pressurized to 9.8 bar before entering the PRO membrane. Water flux and maximum power density of the PRO membrane were $3.7 \mathrm{~L} /$ $\mathrm{m}^{2} \mathrm{~h}$ and $1.0 \mathrm{~W} / \mathrm{m}^{2}$, respectively. The maximum power density achieved by the PRO process was only $20 \%$ of the threshold recommended by Statkraft Company for an economic osmotic power plant. This confirms the outcomes of the previous work by Statkraft Company and concluded that seawater-river water salinity gradient is an uneconomic source for power generation with the PRO process.

\section{Advances in the PRO Process}

Osmotically driven processes suffer from self-deficiencies due to the effects of diluted and concentrated concentration polarization taking place at the draw and feed solutions, respectively. As fresh water permeates across the membrane, the draw solution becomes more diluted while the feed solution gets more concentrated and hence reduces the osmotic pressure driving force across the membrane. The phenomenon of concentration polarization is inevitable in the PRO and FO processes and has detrimental effect on the process efficiency. Recently, Altaee et al. [12] proposed a dual stage PRO (DSPRO) process in an attempt to reduce the impact of concentration polarization and enhancing the performance of the osmotic power plant [12]. In practice, feed concentration in osmotically driven membrane processes tends to reduce the osmotic pressure gradient and water flux. Unlike pressure driven membrane processes in which concentration polarization occurs on the feed side, osmotically driven membrane processes suffer concentration polarization on both sides of the membrane. In the DSPRO process, the concentrated draw solution from the first stage of the PRO process is replaced with fresh draw solution for fresh water exchange with the already pressurized draw solution from the first stage (Figure 1). Theoretical studies have shown that DSPRO process is able to increase the energy yield of the PRO process more than $18 \%$ [12]. Ignoring the membrane fouling issues, studies have shown that DSPRO process is more effective with feed solution of high concentration such seawater or RO brine. DSPRO does not require a an extra high pressure pump on the draw solution since the pressurized draw solution from the first stage PRO process will be recycled to the second stage.

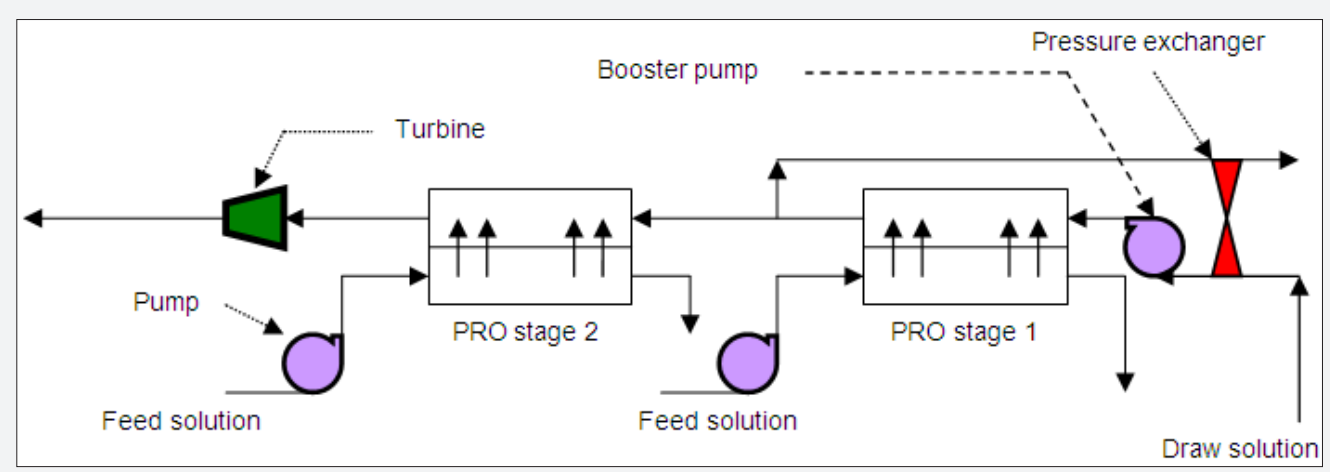

Figure 1: Schematic diagram of the Dual Stage Pressure Retarded Osmosis Plant.

The second stage of the DSPRO process requires a small membrane area because the flow rate of the draw solution will be equal to the permeate flow in the first stage of the DSPRO process. A part of the pressurized draw solution equal to the initial flow rate of the draw solution is recycled to a pressure exchanger after leaving the first stage of the DSPRO process to exchange pressure with the draw solution as shown in Figure 1. Furthermore, the cost of PRO membrane has been brought down since Statkraft pilot plant demonstration. The cost of Toyobo hollow fiber PRO membrane, HP10 Series, is similar to that of the 
R0 membrane. The membrane has an active area of $700 \mathrm{~m}^{2}$ and stands 30 bar feed pressure which make it a good fit for many salinity gradient resources.

\section{Conclusion}

Osmotic power plant is a new source of renewable energy that can be further developed for power generation. Despite the large number of laboratory scale studies, only few pilot plant tests were attempted. Power generation from a salinity gradient resource is highly affected by the concentration of feed and draw solutions and the characteristics of the PRO membrane. PRO membranes are commercially available and can be ordered from Toyobo or Toray at a competitive price to the RO membranes. Experimental work also revealed that DSPRO process is able to enhance the performance of the PRO process by reducing the effect of concentration polarization at the feed side. More pilot plant studies are required to demonstrate the advantages of DSPRO process. This will encourage more research and investment on the osmosis power plant as a replacement to the conventional fossil fuel powered power plants.

\section{References}

1. Loeb S, Hessen FV, Shahaf D (1976) Production of energy from concentrated brines by pressure-retarded osmosis: II. Experimental results and projected energy costs. J Membr Sci 1: 249-269.

2. Loeb S, Honda T, Mehta GD (1990) Comparative mechanical efficiency of several plant configurations using a pressure-retarded osmosis energy converter. Journal of Membrane Science 51(3): 323-335.

3. Altaee A, Sharif A (2015) Pressure Retarded Osmosis: Advancement in the Process Applications for Power Generation and Desalination. Desalination 356: 31-46.
4. Achilli A, Cath TY, Childress AE (2009) Power generation with pressure retarded osmosis: An experimental and theoretical investigation. Journal of Membrane Science 343(1-2): 42-52.

5. Kim YC, Elimelech M (2013) Potential of osmotic power generation by pressure retarded osmosis using seawater as feed solution: Analysis and experiments. Journal of Membrane Science 429: 330-337.

6. Altaee A, Zhou J, Alanezi AA, Zaragoza G (2017) Pressure retarded osmosis process for power generation: Feasibility, energy balance and controlling parameters. Applied Energy 206: 303-311.

7. Touati K, Tadeo F (2016) Study of the Reverse Salt Diffusion in pressure retarded osmosis: Influence on concentration polarization and effect of the operating conditions. Desalination 389: 171-186.

8. Schiestel T, Hänel C, Öxler L, Roelofs K, Walitza E, et al. (2012) Celluloseacetate mem-branes with an optimized internal structure for pressure retarded osmosis. Procedia Engineering 44: 2124-2136.

9. Kurihara M, Hanakawa M (2013) Mega-ton Water System: Japanese national research and development project on seawater desalination and wastewater reclamation, Desalination 308: 131-137.

10. Keiichiro S, Morihiro I, Shintaro Z, Hideyuki S, Hidechito H, et al. (2012) Power generation with salinity gradient by pressure retarded osmosis using concentrated brine from SWRO system and treated sewage as pure water. Desalination and Water Treatment 41(1-3): 114-121.

11. Kim YC, Kim YS, Dongwook Oh, Lee KH (2013) Experimental investigation of a spiral-wound pressure-retarded osmosis membrane module for osmotic power generation. Environ Sci Technol 47(6): 2966-2973.

12. Altaee A, Zaragoza G, Drioli E, Zouh J (2017) Evaluation the Potentia and Energy Efficiency of Dual Stage Pressure Retarded Osmosis Process. Applied Energy 199: 359-369.

Your next submission with Juniper Publishers will reach you the below assets

- Quality Editorial service

- Swift Peer Review

- Reprints availability

- E-prints Service

- Manuscript Podcast for convenient understanding

- Global attainment for your research

- Manuscript accessibility in different formats

( Pdf, E-pub, Full Text, Audio)

- Unceasing customer service

Track the below URL for one-step submission https://juniperpublishers.com/online-submission.php 